\title{
A importância histórica, socioeconômica e ambiental da cacauicultura para o estado de Rondônia
}

O presente trabalho se insere no ramo de tecnologia agrícola sustentável, mais precisamente na cacauicultura em Sistemas Agroflorestais (SAFs). Para tanto, teve como objetivo geral analisar a importância histórica, socioeconômica e ambiental da cacauicultura para Rondônia. Tratou-se de um estudo exploratório e descritivo, que teve uma abordagem qualitativa. Por meio de análise do contexto histórico da cacauicultura em Rondônia através das teorias de desenvolvimento conclui-se que a implantação comercial de cacau no Estado, apesar de ter iniciada na década de 1960, período esse após a abolição da escravatura, o seu planejamento não atendeu os requisitos mínimos do modelo de desenvolvimento local, mas sim um modelo em que os beneficiários são os outsiders. Conclui-se ainda que, com a área plantada de cacau ainda existente em Rondônia, havendo uma política pública envolvendo todos os stakeholders do ramo do cacau incluindo a comunidade técnica, científica e acadêmica, o Estado tem um potencial de produzir cerca de 16 mil toneladas de cacau por ano, atendendo a uma produtividade média de cerca de $1.200 \mathrm{~kg} / \mathrm{ha} / \mathrm{ano}-1$. Não obstante a produção de cacau em SAFs poderiam trazer inúmeros benefícios sociais e ambientais, tais como manutenção das condições de habitabilidade do planeta, manutenção dos ciclos biogeoquímicos, manutenção do clima, oferta de paisagem, proteção de mananciais hídricos, proteção da diversidade de genes e espécies, estoque de carbono, produção agrícola, dentre outros.

\section{The historical, socio-economic and environmental importance of cocoa farming for the state of Rondonia}

\begin{abstract}
The present work is inserted in the field of sustainable agricultural technology, more precisely in cacao cultivation in Agroforestry Systems (SAFs). So, its general objective was to analyze the historical, socioeconomic and environmental importance of cacao cultivation for the State of Rondonia. It was an exploratory and descriptive study, which took a qualitative approach. Through an analysis of the historical context of cocoa cultivation in Rondonia through development theories it is concluded that the commercial implantation of cocoa in the Statea, despite having started in the 1960s, a period after the abolition of slavery, its planning it did not meet the minimum requirements of the local development model, but a model in which the beneficiaries are outsiders. It is also concluded that, with the cocoa planted area still existing in Rondônia, with a public policy involving all stakeholders in the cocoa branch, including the technical, scientific and academic community, the state has the potential to produce around 16 thousand tons of cocoa per year, attending an average productivity of about 1,200 kg/ha/year-1. Nevertheless, cocoa production in SAFs could bring countless social and environmental benefits, such as maintaining the planet's habitability conditions, maintaining biogeochemical cycles, maintaining the climate, offering the landscape, protecting water sources, protecting the diversity of genes and species, carbon stock, agricultural production, among others.
\end{abstract}

Keywords: Devlopment; Agroforestry systems; Theobroma cacao.

Topic: Desenvolvimento, Sustentabilidade e Meio Ambiente

Reviewed anonymously in the process of blind peer.
Received: 06/02/2020

Approved: 04/03/2020

Juocerlee Tavares Guadalupe Pereira de Lima (id

Universidade Federal de Rondônia, Brasil http://lattes.cnpq.br/8757770206623811 http://orcid.org/0000-0002-2615-7781

juocerlee@unir.br

Rodrigo Barros Rocha (iD)

Embrapa, Brasil

http://lattes.cnpq.br/8295625748916004

http://orcid.org/0000-0001-5275-5315

rodrigo.rocha@embrapa.br

Referencing this:

LIMA, J. T. G. P.; ROCHA, R. B.. A importância histórica, socioeconômica e ambiental da cacauicultura para o estado de Rondônia. Revista Ibero Americana de Ciências Ambientais, v.11, n.2, p.314-332, 2020. DOI: http://doi.org/10.6008/CBPC21796858.2020 .002 .0030 


\section{INTRODUÇÃO}

O cacau (Theobroma Cacao L.), fruto que dá origem ao chocolate através do processamento das suas sementes secas (amêndoas) teve as suas origens na região amazônica e é cultivada nas regiões tropicais de todo o mundo. Há registros históricos que foi domesticado pelos Maias na América Central muito antes da chegada dos europeus ao continente americano (CUATRECASAS, 1964). Entretanto, novas evidências científicas indicam que os povos Mayo-Chinchipe já utilizavam o cacau há mais de 5.300 anos, na região do Equador (ZARRILLO et al., 2018).

Sendo bastante apreciada, tanto pelos colonizadores das américas, quanto pelos seus nativos, o seu cultivo comercial se iniciou no Brasil por volta de 1679. Assim várias tentativas foram feitas visando à implantação da lavoura cacaueira em outras regiões com condições edafoclimáticas semelhantes à região amazônica. Nesse contexto, gradativamente as suas sementes foram se disseminando pelo Brasil e pelo mundo. O primeiro registro fora da Amazônia Brasileira foi no Sul da Bahia, em meados do século XVIII, enquanto fora das Américas as sementes chegaram na metade do século XIX, sendo o primeiro local o continente africano (SEIBERT, 2015).

No Brasil o cacau se adaptou inicialmente em 6 (seis) estados (Bahia/BA, Pará/PA, Rondônia/RO, Espírito Santo/ES, Amazonas/AM e Mato Grosso/MT), chegando a marca produtiva de cerca de 473 mil toneladas no ano de 1985 e alcançando mais de 66 mil propriedades, sendo a maior parte de agricultura familiar (SILVA NETO et al., 2001; IBGE, 2019). Entretanto, a segunda metade da década de 1980 foi marcada pela queda brusca da produção do cacau no país, ocasionado, principalmente pela infestação da vassourade-bruxa (ESALQ, 2016).

Ocupando o 4ำ (quarto) lugar na produção do cacau no Brasil (IBGE, 2019), o Estado de Rondônia, objeto do contexto espacial do presente trabalho, tem um potencial ímpar para a cultura do cacau, devido às características edafoclimáticas da região (ALMEIDA et al., 2011). Com o cultivo comercial iniciado 1968, o Estado chegou a produzir cerca de 20 mil toneladas em finais da década de 1980. Entretanto, na última década, registrou um decréscimo de produção na ordem de 70\%, produzindo apenas pouco mais de 5 mil toneladas. Em contrapartida, atividades agropecuárias como o cultivo de soja e criação de gado bovino está em ascensão em Rondônia (TEIXEIRA NETO, 2017; IBGE, 2019).

Economistas ecológicos defendem o investimento em tecnologias sustentáveis, ou seja, investimentos em tecnologias que geram eficiência de recursos, que substituam tecnologias convencionais, e que fortaleçam o ecossistema (JACKSON, 2013). Uma dessas tecnologias, no ramo agropecuário é o Sistema Agroflorestal (SAF), que consiste em sistemas de manejo sustentável do solo que eleva a sua produtividade total, considerando-se as produções florestais, agrícolas e/ou pecuárias, simultaneamente, na mesma unidade de área, onde são aplicadas técnicas de manejo compatíveis com as tradições culturais da população local (KING et al., 1978). A cacauicultura é uma das atividades agrícolas que mais utiliza o Sistema Agroflorestal (SAF) no continente africano e na América Latina e Caribe (OKE et al., 2007; TEIXEIRA NETO, 2017; SILVA, 2018). Apesar desta alternativa ecológica, tem-se registrado abandono de áreas plantadas de 
cacau em todas as regiões produtoras do Brasil, sendo indicadas como maiores motivações, a baixa produtividade, a oscilação do preço do mercado internacional (ZUGAIB et al., 2015) e a infestação por principais doenças de cacau (ESALQ, 2016).

É nessa perspectiva que o trabalho aborda o cacau em Sistema Agroflorestal como tecnologia agrícola sustentável, trazendo um contexto histórico e socioeconômico e ambiental, tendo como o foco o Estado de Rondônia, tentando assim, responder o seguinte questionamento: Qual a importância histórica, socioeconômica e ambiental da cacauicultura em Sistemas Agroflorestais para o Estado de Rondônia? Para se atender o tal questionamento, o trabalho teve como objetivo geral a seguinte proposição: analisar a importância histórica, socioeconômica e ambiental da cacauicultura para o Estado de Rondônia.

O resultado do estudo poderá trazer discussões acadêmicas e políticas sobre a importância histórica do cultivo do cacau e recuperação de áreas degradadas dessa cultura no Estado, como um dos mecanismos para a distribuição de renda rural. Dessa forma, estudos que preencham essa lacuna são relevantes para a epistemologia do conhecimento desse setor na economia do Estado. Não obstante, a motivação científica do estudo se concentra na importância da cacauicultura em sistemas agroflorestais (SAFs), como mecanismos de prevenção do desmatamento. Por outro lado, o trabalho fará paralelos entre estudos anteriores já realizados, tanto no brasil, como no exterior, mostrando casos de interesses socioeconômicos e ambientais ligados a cacauicultura.

\section{REVISÃO TEÓRICA}

\section{A origem e a evolução histórica da trajetória do cacau pelo mundo}

O cacau (Theobroma cacao L.) é uma das 22 espécies pertencentes ao gênero Theobroma que a sua semente é economicamente explorada. De acordo com Cuatrecasas (1964) o cacau foi batizado em 1753 como Theobroma cacao ou alimento dos deuses pelo botânico sueco Carl Von Linneaus, sendo que há registros históricos que a sua exploração foi inicialmente introduzida pelos Maias na América Central, muito antes da chegada dos europeus ao continente americano, que tinha o seu cultivo e colheita ligados a atividades religiosas. Entretanto, descobertas arqueológicas recentes indicam que os povos Olmecas já utilizavam o cacau bem como o chocolate em seus rituais há mais de 3.000 anos (POWIS et al., 2011) e os povos Mayo-Chinchipe, há mais de 5.300 anos (ZARRILLO et al., 2018).

Por um lado, um estudo publicado em 2011 por uma rede de pesquisa composta por integrantes do Instituto de Investigações Antropológicas da Universidade Nacional Autónoma do México, Departamento de Nutrição e o Departamento de Toxicologia Ambiental da Universidade de Califórnia, bem como do Departamento de Antropologia da Universidade Trent do Canadá, trouxe evidências científicas de presença de materiais biológicos provenientes do cacau datados entre 1800 e 1000 a.C., em San Lorenzo (México), a antiga capital dos povos Olmecas. $\mathrm{O}$ estudo documenta ainda as formas variadas dos artefatos utilizados na preparação e consumo de bebidas feitas a partir do cacau, de acordo com a Figura 1 (POWIS et al., 2011). 




Figura 1: Amostra de artefatos arqueológicos utilizados pelos Olmecas entre 1800 e 1000 a.C., para armazenar, preparar e servir cacau e seus derivados. Fonte: Powis et al. (2011).

Esses artefatos arqueológicos eram utilizados pelos Olmecas, mais precisamente no auge da civilização de San Lorenzo (1800-1000 a.C.), para o uso do cacau e dos seus derivados, como parte de um ritual mortuário para vítimas acidentais (POWIS et al., 2011).

Por outro lado, pesquisas mais recentes, realizadas no sítio arqueológico de Santa Ana-La Flórida no Equador, lideradas por Sonia Zarrillo e Michael Blake da University of British Columbia, da qual participaram mais de uma dúzia de pesquisadores internacionais, cujos resultados foram publicadas no periódico Nature Ecology and Evolution em 2018, trouxeram evidências arqueológicas que indicam o uso de cacau pelos povos Mayo-Chinchipe, há mais de 5.300 anos, sendo considerada a mais antiga evidência de uso de cacau nas américas, como pode ser observado nos artefatos arqueológicos (FIGURA 2) utilizados, que deram positivo para a presença de DNA de Theobroma cacao (ZARRILLO et al., 2018).

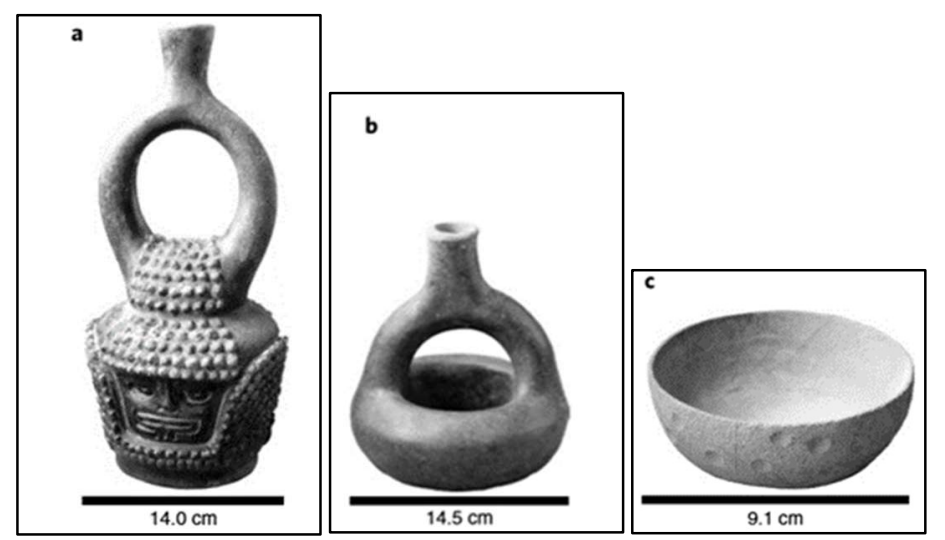

Figura 2: Amostra de artefatos arqueológicos utilizados pelos Mayo-Chinchipe nos anos 3.500 a.C., para armazenar, preparar e servir cacau e seus derivados. Legendas: a) garrafa de estribo em forma de efígie humana; b) garrafa de estribo em forma de rosquinha; c) tigela de pedra com ranhuras em incisão. Fonte: Adaptada de Zarrillo et al. (2018).

Essas evidências arqueológicas indicam que os ancestrais dos povos Maias não foram os primeiros a domesticarem o cacau nem os pioneiros na preparação do chocolate, mas sim herdaram essa cultura de outros povos antigos que habitavam a região equatorial das américas, uma vez que o domínio Maia só iniciou em 1.000 a.c.

Quanto ao primeiro contato dos europeus com o cacau, há registros históricos que foi no século XV quando os mesmos observaram que as sementes de cacau secas eram utilizadas pelos Maias como moeda de trocas e de pagamento de tributos. Além disso, observaram que as suas sementes eram utilizadas em cerimônias de nascimento e como presente de casamento e ainda eram guardados pelos imperadores desse povo, como símbolo de riqueza e poder (KIM, 2007). Apesar de ter a sua origem nas cabeceiras do Rio 
Amazonas, as suas sementes foram se expandindo em duas direções principais, originando duas variedades conhecidas como: Criollo e Forastero. De acordo com Cuatrecasas (1964), além de essas duas variedades, existe outra explorada comercialmente, o trinitário, que é uma variedade híbrida resultante do cruzamento natural entre as variedades criollo e forasteiro acontecidos na ilha de Trinidad (Trinidad e Tobago). Lima et al. (2017) sugerem que em torno do séc. XVIII os espanhóis encontraram um centro de diversidades de cacaueiros no sul do México e na América Central, que possivelmente tinham sido cultivados pelos Maias.

Apesar de várias versões sobre a origem geográfica do cacau, os seus primeiros domesticadores e exploradores, sabe-se que a sua expansão, pelo mundo a fora, foi devido ao império europeu na era dos descobrimentos e expansão. Há registros históricos que o primeiro cultivo comercial do cacau se deu na ilha de Trinidad (Trindade e Tobago) em 1525, quando os colonizadores espanhóis plantaram a variedade criollo na ilha, trazida de populações silvestres da Venezuela. Já no séc. XVIII, precisamente no ano de 1757, foi introduzida a variedade forasteiro nas ilhas, também trazida da Venezuela, dando origem assim a variedade 'trinitário', que pela sua resistência às principais doenças de cacau, bem como a sua alta produtividade, fez com que Trinidad e Tobago se transformasse em um dos maiores produtores do cacau no mundo, no ano de 1830 (BEKELE, 2004).

O primeiro registro histórico sobre o cultivo do cacau no período pós-descobrimento da Venezuela foi feito em 1761 pelos frades franciscanos (Ordem dos Frades Menores Capuchinhos) quando os mesmos começaram a colonizar a população indígena. Um relatório oficial indicava que em torno de Carúpano e do vizinho Rio Caribe existiam 40 plantações com mais de 53.000 cacaueiros, que produziam uma safra anual de aproximadamente 15 toneladas (VALLENILLA, 1996). Entretanto, Kim (2007) pontua que a história comercial do cacau na Venezuela remota desde o iniciou na segunda metade da década 1520, cerca de 30 anos após o descobrimento do território pelo navegador espanhol Cristóvão Colombo.

Já no Brasil o cultivo comercial iniciou oficialmente em finais da década de 1670, com a autorização na Carta Régia para os colonizadores fazerem a sua plantação no Pará, uma vez que a cacauicultura se destacou como a maior fonte de riqueza do vale amazônico na altura. No entanto, o cultivo do cacaueiro na região se dava em pequena escala porque a maior parte das sementes era obtida em árvores espalhadas pela floresta (PRADO JÚNIOR, 1978). Não obstante, o porto que atendia o escoamento de toda a produção da Amazônia Brasileira estava em local inadequado e não apresentava condições adequadas de estocagem, como a higiene e a baixa umidade. Era localizado na chamada região dinâmica, onde havia sido fundada a capital Belém, implicando fretes altíssimos, tanto pelos pequenos volumes a serem exportados, quanto pelas dificuldades de aportes de barcos oriundos da Europa e dos Estados Unidos da América (EUA). Nessa conjuntura, os comerciantes preferiam utilizar os portos de Recife/PE e Salvador/BA, acarretando maiores custos (MARTA, 2018). Esse cenário foi se mudando após a introdução do cacau no Sul da Bahia na primeira metade do século XVIII.

A história do cacau na Bahia se inicia em 1746, quando um agricultor baiano, Antonio Dias Ribeiro, recebeu de um colonizador francês do Pará, Louis Frederic Warneaux, algumas sementes de cacau da variedade forastero e introduziu o cultivo no sul da Bahia. A planta se adaptou bem na região, devido as suas 
características edafoclimáticas, passando a liderar a produção nacional no início do séc. XX (ASSAD, 2017). Assim, no final do século XIX, a cultura de cacau passou a ser considerada como uma importante atividade econômica, com o viés exclusivamente lucrativo, quando o capital comercial começa a preponderar como incentivador da sua evolução no sul da Bahia.

Na primeira metade do séc. XIX a cultura do cacau foi se espalhando por outros continentes. O primeiro local fora das Américas a ter a plantação comercial do cacau foi São Tomé e Príncipe (antiga colônia Portuguesa formadas por 2 ilhas, localizadas na Costa Ocidental Africana), quando por volta de 1855 foi levado do Sul da Bahia até essas ilhas (CEPLAC, 2019). Entretanto, há registros históricos que as primeiras sementes foram introduzidas na ilha do Príncipe em 1822, como planta ornamental, na época em que a economia de São Tomé e Príncipe era baseada na monocultura do café arábica (Coffea arabica) (SEIBERT, 2015).

Após São Tomé e Príncipe, o cacau foi levado para as ilhas vizinhas de Fernão Pó (atual Bioko), pertencente à Guiné Equatorial, que por sua vez fez chegar ao continente entre a década de 1910 e 1920, se iniciando na antiga Costa do Ouro, que é a atual Gana (OFORI et al., 2016) e no Oeste da Nigéria, e posteriormente à Costa do Marfim. Assim, no período que se seguiu ao fim da Segunda Guerra Mundial, mais precisamente o declínio e a abolição do regime colonial, surgiram novos produtores de cacau na África e na Ásia. Regulações mais flexíveis sobre a proteção das reservas florestais e a mobilidade do trabalho desempenharam um papel importante nesse processo. Com isso, após 1960 a Costa do Marfim abriu suas reservas florestais e acolheu imigrantes do interior do Sudão para trabalhar nas plantações e se consagrou como o maior produtor mundial de cacau (CHAUVEAU et al., 1996).

Assim, a plantação de cacau se estendeu por toda o espaço geográfico do Cinturão Tropical, ou seja, desde a região central das Américas, passando da costa ocidental do Continente Africano, até a área entre o sul do Continente Asiático e o norte da Oceania, como se observa na Figura 3.

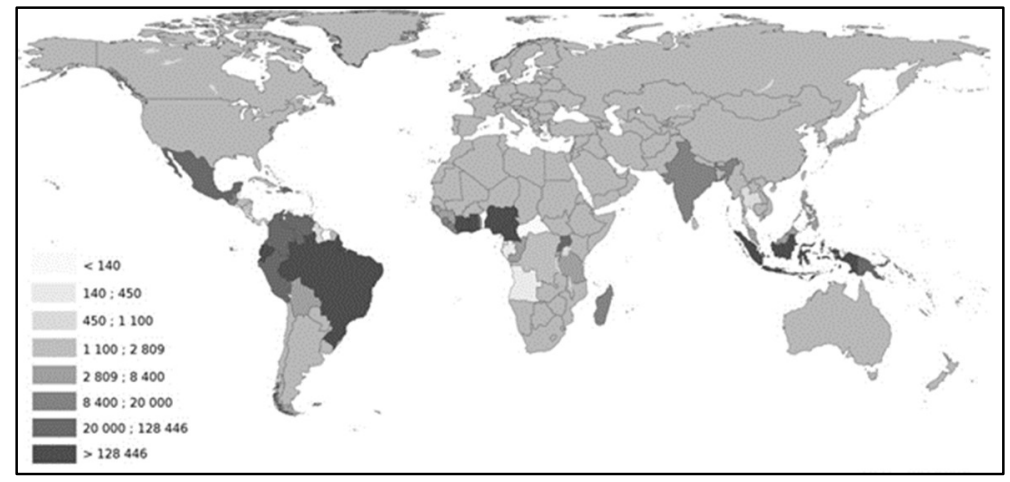

Figura 3: Mapa de diferentes regiões produtoras do cacau no mundo. Fonte: WASC (2016).

Pode-se observar na Figura 3 que a produção do cacau no mundo se concentra na região de florestas tropicais, se estendendo da América Central, Caribe e o centro-norte da América Latina, passando da Costa Ocidental Africana até o sul do continente asiático e a Oceania. Assim apesar da bacia amazônica ser o centro de origem do cacau e consequentemente um dos principais centros de diversidades, o continente africano se destaca no ranking mundial, sendo responsável por cerca de $70 \%$ desse mercado. 
A Costa do Marfim lidera a produção mundial com cerca de 1,8 milhões de toneladas de amêndoas de cacau, seguida por Gana com cerca de 800 mil toneladas, representando cerca de $41 \%$ e $20 \%$ da produção mundial, respectivamente. O terceiro maior produtor de cacau do mundo é a Indonésia com a produção de cerca de 400 mil toneladas, seguida por Nigéria com uma produção de cerca de 300 mil toneladas. Já o Brasil, ocupa a 5a posição, com pouco mais de 250 toneladas (ZUGAIB et al., 2015).

No Brasil o ranking é liderado pelo Estado da Bahia com cerca de $54 \%$ da produção local, a seguir é o Estado do Pará com cerca de 40\%. O 3 (terceiro) lugar é ocupado pelo Estado do Espírito Santo, com pouco mais de $2,5 \%$ da produção nacional, enquanto Rondônia ocupa o 4ㅇ (quarto) lugar no ranking com $2,4 \%$ da produção.

\section{A trajetória do cacau no Estado de Rondônia}

O Estado de Rondônia já foi um dos principais produtores de cacau do país. O registro histórico data de 1790, do qual se descreve a ocorrência de populações silvestres de cacaueiros na ocasião da demarcação de limites de terra entre Portugal e Espanha. No registro narra-se a abundância de madeiras de qualidade e de 'drogas do sertão', sendo uma delas o cacau, às margens do Rio Madeira e às margens da antiga Estrada de Ferro Madeira Mamoré, precisamente na localidade de Chocolatal, região hoje que pertence ao município de Nova Mamoré (ALMEIDA et al., 2011).

Apesar de ter sido registrada a ocorrência em 1790, o seu plantio comercial em Rondônia iniciou-se apenas em 1968, quando o Instituto Brasileiro de Reforma Agrária (IBRA), posteriormente denominado de Instituto Nacional de Colonização e Reforma Agrária (INCRA), solicitou ao Centro de Pesquisa de Cacau (CEPEC), antiga Comissão Executiva do Plano da Lavoura Cacaueira (CEPLAC), um estudo de viabilidade para o cultivo dessa planta na região, uma vez que o sucesso era gritante no Sul da Bahia (AFONSO, 2008).

Foi nesse período que a colonização oficial do então Território Federal do Guaporé ganhou forças e imprimiu uma nova configuração na sua ocupação. Pois, antes, com o fim dos 2 (dois) ciclos da borracha, ocasionados com o fim da segunda guerra mundial e com a exploração das seringueiras no continente asiático, respetivamente, o processo de povoamento e a atividade econômica da região estava em decadência, vivendo basicamente do extrativismo. Assim, ocorreu o processo de assentamento do INCRA, para a região distribuindo pequenas propriedades de, em média, 35-50 ha de área arável, destinadas a migrantes descapitalizados que se deslocaram para a região, com propósito de melhores meios de vida com plantios de plantas perenes, do qual incluía o cacau (SYDENSTRICKER NETO, 1992).

Nesse contexto, o convênio celebrado entre INCRA e CEPLAC, em 1971, tornou a atividade cacaueira alternativa de exploração para a ação colonizadora e desenvolvimentista implementada pelo INCRA na região, o que possibilitou a criação de polos cacaueiros fora das tradicionais zonas produtoras do Sul da Bahia, que detinha, na época, cerca de 95\% da produção brasileira (RODRIGUES SOBRINHO et al., 2011). Assim, inicialmente em 1971 foram plantados 1.000 (mil) cacaueiros na região de Ouro Preto do Oeste-RO, na Estação Experimental da CEPLAC e no Projeto Integrado da Colonização do INCRA. Posteriormente, na década de 1980 foram plantados 9.000 (nove mil) cacaueiros em Ariquemes-RO, precisamente nos projetos 
Burareiro e Marechal Dutra. Como parte do projeto de expansão de polos cacaueiros fora do Sul da Bahia, foi criada em 1987, em Ariquemes, a Escola Média de Agropecuária Regional visando a formação de recursos humanos qualificados em técnicas agrícolas para apoiar o crescimento e o fortalecimento da atividade cacaueira na região.

Outro marco temporal sobre a cacauicultura no Brasil que beneficiou Rondônia, foi a implantação do programa do Governo Federal, o Plano de Diretrizes para a Expansão da Cacauicultura Nacional (PROCACAU), que tinha como objetivo implantar 300 mil hectares de novos cacaueiros e a renovação de outros 150 mil hectares em plantações decadentes e de baixa produtividade. Dentre os Estados beneficiados, estava Rondônia com cerca de 100 mil hectares. Entretanto, entraves estruturais, como dificuldade em regulamentação das terras, acesso ao crédito rural, além de carência de rodovias de acesso a todo Estado, só se plantou cerca de 41 mil hectares de cacau no Estado (AFONSO, 2008; CEPLAC, 2019).

Desde então a cultura do cacau foi se expandindo em Rondônia, ocupando cerca de 48 (quarenta e oito) municípios, incluindo a capital Porto Velho. Entretanto, o cultivo de cacau comercial no estado enfrentou vários períodos de crise, ao longo dos últimos 40 (quarenta) anos. Rodrigues Sobrinho et al. (2011) apontam 7 (sete) principais problemas que causarem essa crise: i. Insuficiente conhecimento da enfermidade vassoura-de-bruxa e de condições climáticas da região; ii. Falta de tradição de ações associativas e cooperativas, ficando à mercê dos intermediários; iii. Novo aprendizado para o manejo do cultivo do cacaueiro na região, especialmente no estabelecimento do sombreamento definitivo; iv. Agricultores sem tradição com o cultivo do cacaueiro; v. Agricultores sem conhecimento do uso de tecnologias de cultivo mais avançadas; vi. Aparecimento de novas pragas e doenças e a falta de tecnologias apropriadas para controle; vii. Insuficiência de mão-de-obra qualificada na região.

Além de problemas estruturais ligados a falta conhecimento para combate a principais pragas, bem como falta de tecnologias e mão-de-obra qualificada, a cacauicultura do Estado de Rondônia foi afetada pela baixa de preço do cacau no mercado internacional, na ordem de até 49,4\% entre a década de 1980 e 1990 (ZUGAIB et al., 2015). Esse período de crise ocasionou o abandono e a erradicação de expressivas áreas de cacau, cerca de 35 mil hectares, o que carretou a redução da produção do cacau no Estado, decorrente da baixa produtividade, chegando em média a $300 \mathrm{~kg}$ por hectare. Nesse período, uma parte considerável dessa área foi substituída por área de pastagem (AFONSO, 2008).

Essa primeira fase da crise perdurou até 1994 quando a cotação do cacau no mercado internacional saiu do patamar de US\$1.000,00 por tonelada e em 1996 se iniciou a pesquisa e assistência técnica. Dentro do pacote da assistência técnica proporcionada pela CEPLAC, destaca-se a Difusão e transferência de tecnologias para cacau em Sistemas Agroflorestais e o controle de vassoura-de-bruxa, sendo os programas de melhoramento genético, um dos maiores desafios. Como resultado, em 2005 a cacauicultura ocupava uma área de cerca de 40 mil hectares de Rondônia, atendendo cerca de 9.638 famílias, chegando a produzir cerca de 20 mil toneladas por ano, com uma produtividade média de 600 toneladas por ano, de acordo com o Quadro 1. 
Quadro 1: Os 10 (dez) maiores municípios produtores de cacau em Rondônia (2005).

\begin{tabular}{|l|l|l|l|}
\hline Municípios & Área produtiva (ha) & Produção (ton) & Produtividade (kg/ha) \\
\hline Ariquemes & 7.520 & 4.647 & 618 \\
\hline Jaru & 6.950 & 4.524 & 651 \\
\hline Cacaulândia & 3.885 & 2.459 & 633 \\
\hline Buritis & 3.028 & 1.750 & 578 \\
\hline Ouro Preto do Oeste & 1.945 & 1.175 & 604 \\
\hline Campo Novo de Rondônia & 2.045 & 975 & 477 \\
\hline Theobroma & 950 & 552 & 581 \\
\hline Mirante da Serra & 980 & 530 & 541 \\
\hline Governador Jorge Teixeira & 835 & 481 & 576 \\
\hline Machadinho do Oeste & 800 & 450 & 563 \\
\hline Subtotal & $\mathbf{2 8 . 9 3 8}$ & $\mathbf{1 7 . 5 4 3}$ & $\mathbf{6 0 6 *}$ \\
\hline Outros Municípios & 5.613 & 3.189 & 568 \\
\hline Total Geral & 34.551 & 20.732 & $\mathbf{6 0 0}$ \\
\hline
\end{tabular}

*Corresponde à média da Produtividade média de amêndoas de cacau no Estado de Rondônia

Fonte: Adaptado de Afonso (2008).

Pode-se observar no Quadro 1 que os 3 (três) maiores produtores de cacau eram os Município de Ariquemes, Jaru e Cacaulândia. Ariquemes liderava a produção com 4.647 ton/ano, seguido de Jaru com 4.524 ton/ano e Cacaulândia com 2.459 ton/ano. Esses 3 municípios já foram responsáveis por mais de 53\% da área produtiva e mais de $56 \%$ do total produzido no Estado. Importa informar que o município de Cacaulândia pertencia ao município de Ariquemes, sendo desmembrado em 1992. Isso reforça que a região de Ariquemes foi a maior beneficiada com a criação de polos cacaueiros fora das tradicionais zonas produtoras do Sul da Bahia, entre as décadas de 1970 e 1980.

Entretanto, a cultura de cacau tem vindo a ser ameaçada no estado de Rondônia, como em restante do país, uma vez que a produção caiu de cerca de 20 mil toneladas em 2005/2006 para cerca de 5 mil toneladas na safra de 2018/2019, uma queda de aproximadamente 75\% (IBGE, 2019).

\section{A teoria dos Stakeholders e a cacauicultura}

Numa abordagem com grande destaque nas modernas teorias éticas e da responsabilidade social dos stakeholders, a teoria dos stakeholders defende que uma empresa não deve se pautar apenas pelo interesse dos acionistas ou proprietários, mas também pelos interesses dos outros stakeholders (partes interessadas), nomeadamente os empregados, gestores, comunidade local, clientes e fornecedores (FREEMAN, 1984).

Nas últimas três décadas, a teoria dos stakeholders vem sendo utilizada na tomada de decisões ambientais. Essa evolução reflete uma série dos desenvolvimentos ambientais, políticos, sociais e tecnológicas que começaram a produzir alterações significativas nas tomadas de decisão em relação ao desenvolvimento sustentável. As maiores causas da abordagem dessa teoria no processo de tomada de decisão ambiental são: a falta de confiança do público quanto à credibilidade do governo e das instituições privadas na tomada de decisões ambientais, falta de transparência das instituições cujas decisões afetam a qualidade do meio ambiente; maiores expectativas da sociedade para a melhoria da qualidade do meio ambiente; a necessidade dos cidadãos participarem como stakeholders secundários, a crescente difusão da tecnologia da informação e compromissos políticos feitos por agências governamentais e indústrias para 
incluir partes interessadas nos seus processos de tomada de decisão (YOSIE et al., 1998).

A relação entre desenvolvimento e meio ambiente interfere diretamente nas atividades agropecuárias, uma vez que estas estão no centro de todo o processo que envolve, a utilização de recursos naturais, a geração de resíduos e a capacidade de suporte do planeta, tanto no suprimento de recursos, quanto na recepção de resíduos (BORGES, 2007). Neste cenário as questões ligadas ao desenvolvimento, tem que estar atrelada ao equilíbrio entre o econômico, o social e o meio ambiente, ou seja, um desenvolvimento sustentável. Este conceito, proposto pelo relatório de Brundtland, entende-se como sendo aquele que atende às necessidades do presente sem comprometer a possibilidade de gerações futuras atenderem às suas próprias necessidades (BARBIERI, 2004; NASCIMENTO, 2008).

Corroborando com Barbieri (2004) e Nascimento (2008), Borges (2007) explica que o modelo deve contribuir para gerar renda e riqueza, que são os objetivos básicos das empresas, minimizando seus impactos ambientais adversos, maximizando os benefícios, tornando a sociedade justa. Sendo assim, uma organização que segue modelos de gestão baseados em desenvolvimento sustentável é considerada responsável nas perspectivas econômica, social e ambiental. Além disso, as empresas poderão alcançar a redução de custos, aumento de qualidade, parcerias, benefícios aos stakeholders e novos negócios que possam sustentar uma vantagem competitiva em longo prazo.

No início da década de 1990 o sociólogo e consultor britânico John Elkington formulou o conceito Triple Bottom Line para representar a sustentabilidade de qualquer atividade empresária. O conceito se refere a geração de renda e riqueza, que são os objetivos básicos de qualquer organização que vise lucro, minimizando seus impactos ambientais adversos, maximizando os benefícios, tornando a sociedade justa.

De acordo ao conceito, o econômico se refere a multiplicação do capital investido, o ambiente significa minimizar os impactos ambientais, enquanto a dimensão social é a mais focada aos stakeholders externos. Compreende um comportamento socialmente responsável e antecipador, ou seja, as empresas adotam uma atitude proativa e preventiva. Empresas que adotam esse tipo de abordagem procuram ir além da mera ação social e da reação social, ela busca formas de resolver problemas sociais com pro-atividade, prevendo problemas sociais futuros, incorporando todos os stakeholders nas suas estratégias sociais, pois além de combinarem o lucro com o cumprimento de medidas legais e pressões de diferentes stakeholders, elas, discricionariamente adotam programas sociais nas suas estratégias de negócios, bem como financiam programas sociais que são geridos por Organizações Não Governamentais (ONG), Associações, e etc..

Assim nas últimas 2 (duas) décadas têm surgidas pressões por parte dos stakeholders desse ramo, tentando buscar a sustentabilidade na indústria do cacau, tendo as maiores demandas o desmatamento, a escravidão, trabalho infantil, além de exploração dos pequenos agricultores, quanto aos preços insuficientes pagos aos mesmo pelos atravessadores e/ou grandes indústrias do ramo. Essas pressões criaram uma maior conscientização do consumidor e canalizou grandes quantidades de fundos de pesquisa para as mãos daqueles que buscam soluções que atendem o modelo sustentável (DONALD, 2019). 
A teoria dos Polos de Crescimento de Perroux (1955)

Souza (2005) aborda a teoria dos polos de crescimento de Perroux, envolvendo as noções de indústria motriz, formas de polarização, economias e deseconomias de aglomeração, separatismo ou renúncia de soberania e despolarização, com exemplos de sua aplicação regional. Além disso, liga a teoria dos polos com a abordagem schumpeteriana do desenvolvimento, a teoria do crescimento endógeno e os conceitos de meios inovadores, regiões inteligentes e sistemas regionais de inovação. A ideia é a que a própria teoria dos polos possui uma abordagem endógena, noção realçada pelos conceitos de meios inovadores e afins. Estes são os núcleos das regiões inteligentes, que pressupõe uma periferia.

A ideia básica é a de que a interação entre os agentes locais, formados por empresários, pesquisadores de universidades, técnicos de agências públicas e privadas de pesquisa, entre outros, é fundamental para alavancar a pesquisa tecnológica e a sua aplicação produtiva. Os sistemas de inovação centram-se na ideia de difusão das inovações dos centros nacionais para os regionais, assim como na interação entre todos os stakeholders. Tornam-se imprescindíveis ao desenvolvimento regional instituições eficientes, economias de aglomeração e criação e difusão de novas tecnologias. Isso implica intensa interação e cooperação entre os atores locais do desenvolvimento econômico regional (SOUZA, 2005).

Nessa perspectiva no avanço da indústria de cacau no Brasil, não se levou em conta todo o processo de desenvolvimento, apenas se focou no crescimento econômico ligados às indústrias motriz, gerando apenas crescimento polarizado, uma vez que foram concentrados em torno do Estado da Bahia e do Estado de São Paulo, que concentravam as maiores indústrias chocolateiras. Por outro lado, essas indústrias, por possuírem grande poder de mercado, e consequentemente ligações locais com produtores do cacau, conseguiam influenciar os preços dos produtos, muitas das vezes explorando os produtores locais.

No caso específico de Rondônia, grandes indústrias de chocolateiras se instalaram na região apenas com o intuito de comprar a matéria-prima para abastecer as grandes moageiras localizadas nos estados da Bahia e de São Paulo. Portanto, esse modelo de crescimento, tende apenas o desenvolvimento da região onde se encontram instaladas as indústrias motrizes, e não nas regiões onde é produzida a matéria-prima.

Baseado ainda na abordagem da teoria dos polos de crescimento de Perroux, proposta em Souza (2005), o processo de colonização do estado de Rondônia, mais precisamente na introdução comercial do polo cacaueiro na região entre as décadas de 1960 e 1980 deveria haver uma interação entre os agentes locais, formados por famílias produtoras do cacau, pesquisadores de universidades, técnicos de agências públicas e privadas de pesquisa, entre outros, na alavancagem da pesquisa tecnológica e a sua aplicação no que toca os aspectos sociais e ambientais. Pelo que se entende, a expansão de polos cacaueiros fora do Sul da Bahia, na verdade era para atender as indústrias motrizes desse ramo já instaladas, e não para promover o desenvolvimento local, uma vez que não houve instalação de indústrias locais (geração de renda), nem tampouco utilização de tecnologias sustentáveis de produção de cacau, para garantir preço diferenciado no mercado.

Na mesma linha de pensamento Escobar (2005) aborda a relação da globalização econômica, com 
base em experiências locais, com destaque para a dificuldade de trabalhar realidades locais. Pois com a integração de toda as partes interessadas, tanto local como nacional, alternativas mais sustentáveis poderiam ser implementadas na introdução do cultivo comercial de cacau em Rondônia, uma vez que no binômio sociedade-natureza, o sujeito é visto dentro do ecossistema.

Ribeiro (2008) ao abordar o poder no campo do desenvolvimento, destaca que, se trata de um campo formado por muitas redes e instituições, por forma de 'consorciação', ou seja, a articulações entre os diferentes atores do campo do desenvolvimento. Além disso, desenvolvimento é tratado como uma ideologia e utopia, como um discurso atravessado por categorias culturais ocidentais e vinculado à expansão econômica capitalista. A discussão sobre os 'dramas desenvolvimentistas' permite identificar dois tipos de sujeitos gerados por posições de poder diferentes, os outsiders e os insiders.

Por um lado, os outsiders, constituídos por atores políticos (policy makers) e as instituições mais poderosos do campo de desenvolvimento, pretendendo desta forma planejar o futuro de uma comunidade, sendo eles designados muitas vezes como 'indústria do desenvolvimento'. Esses atores se empenham na reprodução do campo como um todo, já que seus próprios interesses são intimamente conectados à existência do campo do desenvolvimento. Por outro lado, os insiders (comunidade local) formado por atores e instituições menos poderosos, que acaba sendo vulnerabilizados por iniciativas de desenvolvimento que destroem as relações entre povos, seus territórios e suas culturas.

A natureza da distribuição de poder dentro do campo do desenvolvimento dependerá dos processos por meio dos quais as redes são formadas e das características das intervenções institucionais decorrentes do drama do desenvolvimento. Em tais circunstâncias, instala-se uma dicotomia. Por um lado, há os objetivos e racionalidades dos planejadores (outsiders), por outro lado o destino e a cultura das comunidades (insiders).

Na mesma linha de pensamento de Souza (2005), Escobar (2005) e Ribeiro (2008), Bonente et al. (2008) e Lima et al. (2010) buscaram discutir as teorias do desenvolvimento baseado em Perroux (1955). Bonente et al. (2008) buscaram, através de um resgate da transmutação histórica da discussão de desenvolvimento econômico numa discussão fragmentada do surgimento de uma Nova Economia do Desenvolvimento. Pois o conceito de desenvolvimento não se limita apenas ao acúmulo de riquezas e multiplicação de capital, mas também na sua distribuição a toda parte interessada (stakeholders), bem como gerando garantias para a continuidade de gerações futuras se desenvolverem.

Lima et al. (2010), por fim, tinham objetivo de analisar e descrever as principais características de quatro teorias sobre a dinâmica regional desenvolvidas no período pós Segunda Guerra Mundial, nomeadamente a Teoria dos Polos de Crescimento, da Causação Circular Cumulativa, do Desenvolvimento Desigual e da Transmissão Inter-regional de Crescimento e da Base de Exportações, para analisar a sua associação com os principais planos de desenvolvimento do Brasil, entre as décadas de 1950 e 1980. O resultado do estudo mostra que os policy makers procuraram seguir estas recomendações de políticas baseadas em crescimento econômico, entretanto, vários erros de interpretação levaram a resultados menos significativos que os esperados e comprometeram o desenvolvimento de longo prazo. Após período de forte 
intervenção estatal se seguiu uma onda liberal, com várias mudanças, inclusive no mainstream econômico sobre o desenvolvimento regional.

\section{Cacauicultura em SAF como tecnologia de desenvolvimento sustentável local}

Os sistemas agroflorestais são consórcios de culturas agrícolas com espécies arbóreas que podem ser utilizados para restaurar florestas, recuperar áreas degradadas e também servem como fonte de renda para agricultores. Pesquisa sobre SAFs iniciaram no Brasil no final da década de 1980, voltadas para avaliações biológicas e técnicas das interações entre as espécies componentes desses sistemas (ENGEL, 1999).

Os SAFs têm como principal propósito otimizar o uso da terra, conciliando a produção florestal com a produção de alimentos, conservando o solo e diminuindo a pressão pelo uso da terra na agricultura. Áreas de vegetação secundária, sem expressão econômica e social, podem ser reabilitadas e usadas racionalmente por meio desses sistemas. Outro ponto importante é a formação de sistemas ecológicos mais estáveis, com menor input de recursos externos e maior autossuficiência, podendo dessa forma ser considerado como um tipo de prática sustentável. Outrossim, o equilíbrio biológico do sistema reduz o ataque de pragas e de doenças, podendo trazer benefícios econômicos para o produtor (SANTOS et al., 2000).

De acordo com Van Leeuwen et al. (1999) os Sistemas Agroflorestais (SAFs) são mais adequadas para áreas de floresta tropical, como o caso da Amazônia Brasileira, ao invés de processos agrícolas praticados na região, no qual, a floresta é substituída por roças com culturas anuais que são abandonados após 2 (dois) ou 3 (três) anos na agricultura, ou 10 (dez) a 12 (doze) anos para o pasto. As características como alta quantidade de biomassa por unidade de superfície, raízes, que realçam a ciclagem de nutrientes, e cobertura vegetal permanente, que protege o solo contra a erosão e as altas temperaturas, são razões pelas quais os SAFs constituem uma das poucas opções para o uso da terra mais sustentável na Amazônia Brasileira.

O cultivo do cacau formou os primeiros consórcios agroflorestais comerciais implantados no Brasil, por ser uma planta silvestre que suporta muita sombra. Além de gerar recursos financeiros e fixar o homem no meio rural, o sistema conservou recursos hídricos, fragmentos e espécies arbóreos florestais nativas e de inestimável valor para o conhecimento agronômico, florestal e ecológico, principalmente nos grandes corredores da Mata Atlântica do sul da Bahia (LOBÃO, 2007).

Uma vez não cultivado em pleno sol, a cacauicultura por si só é considerada uma atividade agroflorestal, desde que não sejam utilizados agrotóxicos, pois de acordo com Van Leeuwen (1999), um sistema agroflorestal é composto por duas ou mais espécies, das quais, ao menos uma é lenhosa e perene, pois a o termo 'florestal' não quer dizer que a espécie arbórea do sistema deva ser uma espécie originário de uma floresta ou uma espécie madeireira. Na Amazônia, muitos desses sistemas têm apenas árvores frutíferas e cultivos perenes. Um sistema agroflorestal ocupa o mesmo terreno durante muito tempo, porque são necessários 10 (dez), 20 (vinte), ou mais anos, para que as árvores completem seu ciclo. Um sistema agroflorestal é mais complexo que uma monocultura e, geralmente, contém mais de uma espécie de interesse econômico, o que diminui os riscos do empreendimento. Quando uma espécie não produz ou está sem mercado, a outra continua produzindo, fornecendo renda. 
Apesar dos benefícios socioambientais da cacauicultura em SAF, alguns trabalhos têm apontado desvantagens, no que toca a baixa produtividade e a proliferação de doenças associadas a alta umidade, como o caso da vassoura-de-bruxa, quando comparado a monocultura de cacau. Os principais motivos são competição por nutrientes e por água entre o cacaueiro e as plantas consorciadas. No entanto, as complementaridades entre as espécies no uso de recursos podem melhorar a eficiência do uso de recursos e resultar em maior desempenho do sistema, uma vez que o sistema radicular do cacau é superficial (NIETHER et al., 2019).

Assim, com os manejos adequados a cacauicultura em SAF, combinando diferentes espécies nativas pode ajudar a controlar pragas e doenças e a melhorar a oferta de nutrientes, o que é de especial importância no que toca ao quesito socioambiental. Não obstante, os pequenos produtores de cacau em SAF poderão ter benefícios econômicos com a produção de cacau respeitando o meio ambiente, uma vez que está havendo uma crescente demanda dos stakeholders, por cacau e os seus derivados produzidos ecologicamente corretos. Para atender a essa estratificação do mercado do cacau, já existem no país diferentes tipos de classificações atribuídas à produção de amêndoas de cacau, nomeadamente o cacau convencional, o cacau fino ou de aroma (flavour), o cacau orgânico, o cacau com certificação de sustentabilidade e o cacau com certificação de origem, sendo que os que atendem aos padrões ecológicos, chegam a ter um ágio de $10 \%$ acima do preço do mercado (ESTIVAL et al., 2019).

A literatura tem apontado os SAFs como alternativa promissora para propriedades rurais dos países em desenvolvimento, uma vez que integra floresta, culturas agrícolas e pecuária, podendo oferecer alternativas aos problemas da baixa produtividade, de escassez de alimentos e da degradação ambiental generalizada, como se pode observar com os estudos desenvolvidos por Oke et al. (2007), Silva (2018) e Mendonça (2019).

Oke et al. (2007) tinham o objetivo de analisar os serviços ambientais e benefícios sociais que a plantação de cacau em SAFs trariam para famílias de pequenos agricultores de 3 (três) localidades produtoras de cacau em Nigéria. O resultado do estudo trouxe evidências que a cacauicultura em SAF traz benefícios além dos esperados às famílias dos pequenos agricultores, uma vez que cerca de $86,8 \%$ das árvores nas fazendas eram de árvores de frutas, tendo seu papel crucial nos serviços ambientais e no aumento de renda.

Silva (2018) analisou a viabilidade econômica de SAFs de várias culturas, incluindo a cacauicultura, de agricultores familiares no Projeto de Desenvolvimento Sustentável Terra Nossa, localizado nos municípios de Novo Progresso e Altamira no Estado do Pará. O resultado do estudo indicou que a maioria dos SAFs analisados aponta viabilidade econômica de acordo com os indicadores de VPL, TIR e RB/C, possibilitando ao produtor tomar decisões de investimento.

Mendonça (2019) visou analisar a viabilidade de implantação de um corredor ecológico entre as áreas protegidas de Carajás e da Terra do Meio, no Estado do Pará, tendo como uma das principais culturas o cacau em SAF. O resultado indica que o corredor ecológico proposto tem viabilidade técnica e ambiental para ser implantado e que através de manejos agroecológicas é possível integrar os objetivos da produção agropecuária aos da conservação da biodiversidade. 


\section{METODOLOGIA}

De acordo com Collis et al. (2005), o presente trabalho se caracteriza como exploratória e descritiva quanto ao objetivo. Quanto aos meios, a pesquisa se caracteriza como bibliográfica e documental. A técnica utilizada para a coleta dos dados foi a de análise de conteúdo. A análise de conteúdo como técnica de coleta de dados permite compreender e evidenciar indicadores não expressos explicitamente na mensagem (TRIVINOS, 1987; SILVA et al., 2009).

Com o uso da técnica de análise de conteúdo, as informações foram categorizadas de acordo com as etapas propostas por Trivinos (1987). Na primeira etapa (pré-análise) procedeu-se ao mapeamento do registro histórico do cacau, bem como a sua importância socioambiental abordando teorias de desenvolvimento. Na segunda etapa (descrição analítica) o procedimento constituiu a construção do referencial teórico, a partir dos documentos já publicados. Na terceira e última etapa (interpretação referencial) procedeu-se a análise e discussão teórica sobre a importância histórica, econômica e ambiental da cacauicultura, tendo o contexto espacial o estado de Rondônia. Assim, seguindo a abordagem de Creswell (2009), a presente pesquisa é de abordagem qualitativa, uma vez que se concentra na compreensão do problema utilizando o método qualitativo.

\section{RESULTADOS E DISCUSSÃO}

Por muito tempo pesquisadores acreditavam que eram os Maias os pioneiros na domesticação de cacau, uma vez que quando da chegada dos colonizadores espanhóis, por volta do século XV observaram a importância dadas pelos Maias às sementes de cacau e os seus derivados. Entretanto, evidências arqueológicas indicam que a domesticação de cacau ocorreu há mais de 5.300 anos com a civilização do povo Mayo-Chinchipe que habitava a região do Equador. Essas tradições foram seguidas pelos povos Olmecas e posteriormente pelos povos Maias.

A partir do contato com os colonizadores o cacau foi ganhando importância econômica com a expansão do consumo de chocolate. Primeiramente os espanhóis, por meio de mão-de-obra escrava introduziram o cacau na ilha de Trinidad e Venezuela, depois no Brasil, se iniciando primeiramente no estado do Pará. Mas, foi no Sul da Bahia que o cacau passou a ser considerada como uma importante atividade econômica, com o viés exclusivamente lucrativo. Entretanto, o modelo de cultivo de cacau adotado na altura era centrado na mão-de-obra escrava, visando exclusivamente o ganho de capital, sem anteder os requisitos sociais nem os ambientais. Este modelo de exploração econômica, como pontua Ribeiro (2008), dá origem a vulnerabilidades futuras dos atores locais, pois destroem as relações entre povos, seus territórios, suas culturas além do meio ambiente que se insere.

A teoria dos polos de crescimento de Perroux (1955) pode explicar o avanço desse ramo, sem atender a demanda socioecológica (SOUZA, 2005). Pois, a implantação comercial de cacau no Estado de Rondônia, apesar de ter iniciada na década de 1960, período esse após a abolição da escravatura, o seu planejamento também não atendeu os requisitos mínimos do modelo de desenvolvimento local, mas sim um modelo em 
que beneficia os outsiders, uma vez que o intuito era a garantia de fornecimento de matéria-prima para grandes indústrias processadoras dos derivados do cacau, uma vez que com a baixa de preço no mercado de cacau, as pressões dos atores sociais quanto as condições de trabalho nas lavouras, aparecimento de doenças como a vassoura-de-bruxa, bem como a proibição de alguns pesticidas e inseticidas sintéticos, os cenários de área produtiva do cacau no Estado de Rondônia foi mudando, deixando os pequenos agricultores vulneráveis entre os finais da década de 1980 e início da década de 1990, chegando a abandonar cerca de 35 mil hectares, sendo que a maior parte dessa área foi substituída por área de pastagem.

Esse cenário mudou em Rondônia com a mudança do paradigma da produção agrícola no estado. A CEPLAC por meio de conscientização através de programas de extensão rural, passou a interferir em políticas voltadas para o desenvolvimento local, através de difusão e transferência de tecnologias para cacau em SAF e o controle de vassoura-de-bruxa através de introdução de cultivares melhoradas geneticamente para tal efeito. Os resultados positivos foram notórios em 2005, chegando a atingir 9.638 famílias de pequenos agricultores locais. Portanto, houve uma interação entre os agentes locais, formados por pequenos agricultores produtoras do cacau, instituições de pesquisa, universidades, técnicos de agências públicas e privadas de pesquisa, entre outros, na alavancagem da pesquisa tecnológica e a sua aplicação no que toca os aspectos sociais e ambientais, como pontua Souza (2005).

Apesar do cenário econômico e social da produção do cacau ter melhorado em 2005, como resultado de políticas voltados ao modelo de desenvolvimento local, em 2007 se iniciou uma queda brusca da produção de cacau no estado. Está queda tem uma relação inversa com o aumento da área produtiva de soja, bem como da área de pastagem (IBGE, 2019). Essa relação inversa pode indicar que a cultura de cacau está sendo substituída por outras atividades agropecuárias de pouco interesse socioambiental no estado de Rondônia, mais precisamente pela produção de soja e pasto para a criação de gado bovino. Esses dados são preocupantes, no ponto de vista sustentável, uma vez que a soja e o gado são culturas que não prendem o homem ao campo (social), nem tampouco, se preocupam com aspectos ecológicos (ambiental), pelo contrário, a criação de gado, além de demandar desmatamento e pesticidas, como o caso de soja, emitem gás metano prejudiciais ao ecossistema, apesar de serem uma das maiores fontes de incremento da balança comercial brasileira (econômico). A perspectiva do desenvolvimento sustentável é que a atividade do homem sobre a natureza deve atender às necessidades do presente, sem comprometer as necessidades do futuro. Portanto, o máximo de equilíbrio entre os aspectos econômicos, sociais e ambientais (BARBIERI, 2004; NASCIMENTO, 2008).

Outrossim, com a área plantada de cacau ainda existente no estado de Rondônia, estimada em 13.731 hectare (IBGE, 2019), havendo uma política pública envolvendo todos os stakeholders do ramo do cacau, incluindo a comunidade técnica, científica e acadêmica, o estado tem um potencial de produzir cerca de 16 mil toneladas de cacau, atendendo a uma produtividade média de cerca de $1.200 \mathrm{~kg} / \mathrm{ha} / \mathrm{ano}{ }^{-1}$. Esses resultados são possíveis, entretanto todos os stakeholders teriam que estar envolvidos no investimento na recuperação de áreas degradas de cacaueiro, bem como na implantação Sistemas Agroflorestais (SAFs). Não obstante a produção de cacau em SAFs poderiam trazer inúmeros benefícios sociais e ambientais, tais como 
Manutenção das condições de habitabilidade do planeta, manutenção dos ciclos biogeoquímicos, manutenção do clima, oferta de paisagem/amenidades, proteção de mananciais hídricos, proteção da diversidade de genes e espécies, estoque de carbono, reciclagem de resíduos urbano-industriais, produção de madeira, produção agrícola, dentre outros.

\section{CONCLUSÕES}

O presente trabalho propôs analisar a importância histórica, socioeconômica e ambiental da cacauicultura para o estado de Rondônia. O resultado do trabalho a conclusão que o modelo de desenvolvimento do estado de Rondônia ainda está voltado para o modelo de expansão capitalista, do qual os policy makers procuraram seguir recomendações de políticas baseadas em crescimento econômico, deixando de fora o quesito social e ambiental (LIMA et al., 2010).

Portanto, a indústria de cacau avançou no Brasil, mas não se tem o registro sobre o respeito a dimensão ambiental e a dimensão social, ou seja, ao sistema socioecológico envolvente, como um todo. Uma vez que ao se fazer a análise do modelo de desenvolvimento do estado de Rondônia, no contexto de expansão dos polos cacaueiros, observa-se que se tratou de um modelo de expansão econômica capitalista, do qual visou o aumento de insumos para as indústrias chocolateiras, fora do contexto do desenvolvimento da região, deixando a comunidade local mais vulnerável com o modelo implementado. Exemplo disso, é a substituição da área plantada do cacau, por monocultura de soja, uma vez que a cultura de soja, apesar de ter menos preço de mercado do que cacau, possui maior produtividade e demanda menos mão-de-obra, uma vez que é um trabalho $100 \%$ maquinizado, desde a preparação do terreno para semear, até a sua colheita, diferente da cacauicultura. Com isso, pode-se perceber que ainda existe práticas ocidentais vinculadas a expansão econômica capitalista na agricultura do estado, onde o crescimento econômico se confunde com o desenvolvimento econômico (BONENTE et al., 2008; LIMA et al., 2010).

Nesse âmbito pode-se afirmar que o estudo atingiu o objetivo proposto, deixando a sua contribuição para a epistemologia do conhecimento na área que envolve a história do cacau, bem como a sua importância no desenvolvimento socioeconômico e ambiental, quando implantada em SAFs. Por outro lado, as discussões tecidas ao longo do trabalho poderão servir para tomada de decisão política para órgãos que fomentam a agricultura no estado, sendo ainda aberto para pesquisa futuras que sanem algum tipo de lacuna apresentada no trabalho.

\section{REFERÊNCIAS}

ALMEIDA, C. M. V. C.; MATOS, P. G. G.; DESTRO, W. Contribuições da CEPLAC para o processo de colonização de Rondônia: 40 anos de história e prospectiva. Porto Velho: CEPLAC/SUERO, 2011.

AFONSO, F. M. A.. Rondônia: ocupação, crescimento e organização agrária. Fortaleza: Realce, 2008.

ASSAD, L.. Cacau no Brasil: uma oportunidade que (ainda) não se concretizou. Cienc. Cult., Campinas, v.69, n.2, p.11-
13, 2017. DOI: http://dx.doi.org/10.21800/2317$\underline{66602017000200005}$

BARBIERI, J. C.. Gestão ambiental empresarial. São Paulo: Saraiva, 2004.

BEKELE, F. L.. The history of cocoa production in Trinidad and Tobago. In: Proceedings of the APASTT Seminar. Exhibition entitled Re-vitalisation of the Trinidad \& Tobago Cocoa Industry. St. Augustine: APASTT, 2003. p.4-12. 
BONENTE, B. I.; ALMEIDA FILHO, N.. Há uma nova economia do desenvolvimento?. Revista de Economia, Curitiba, v.34, n.1, 2008

BORGES, F. H.. O meio ambiente e a organização: um estudo de caso baseado no posicionamento de uma empresa frente a uma nova perspectiva ambiental. Dissertação (Mestrado Engenharia da Produção) Universidade de São Paulo, São Paulo, 2007.

CEPLAC. Comissão Executiva do Plano da Lavoura Cacaueira. Cacau: história e evolução. Brasília: CEPLAC, 2019.

CHAUVEAU, J. P.; LÉONARD, E.. Côte d'Ivoire's pioneer fronts: historical and political determinants of the spread of cocoa cultivation. In: SMITH, W. G. C.. Cocoa pioneer fronts since 1800. London: Palgrave Macmillan, 1996. p.176-194. DOI: https://doi.org/10.1007/978-1-349-24901-5 10

COLLIS, J.; HUSSEY, R.. Pesquisa em Administração: um guia prático para alunos de graduação e pós-graduação. 2 ed. Porto Alegre: Bookman, 2005.

CRESWELL, J. W.. Research design: qualitative, quantitative, and mixed methods approaches. 3 ed. Los Angeles: Sage, 2009.

CUATRECASAS, J.. Cacao and its allies: a taxonomic revision of the genus Theobroma. Contributions of the United States National Herbarium, Washington, v.35, n.6, p.379-614, 1964.

DONALD, M.. A shaded understory: interacting with associated species in trinidadian cacao agroforestry systems. Dissertação (Mestrado em Comunicação, Saúde e Ciências da Vida) - Universidade de Wageningen, Wageningen, 2019.

ENGEL, V. L.. Introdução aos Sistemas Agroflorestais. Botucatu: FEPAF, 1999.

ESALQ. Escola Superior de Agricultura "Luís de Queiroz" da Universidade de São Paulo. Novo cenário da produção de cacau no Brasil. Piracicaba: ESALQ, 2016.

ESCOBAR, A.. O lugar da natureza e a natureza do lugar: globalização ou pós-desenvolvimento?. In: LANDER, E. A colonialidade do saber: eurocentrismo e ciências sociais. Perspectivas latino-americanas. Buenos Aires: CLACSO, 2005. p.133-168.

ESTIVAL, K. G. S.; CORRÊA, S. R. S.; PROCÓPIO, D. P.. Construção dos mercados de qualidade do cacau no Brasil. Rev. Agr. Acad., Imperatriz, v.2, n.1, p.103-123, 2019. DOI: https://doi.org/10.32406/v2n12019/103-123/agrariacad

FREEMAN, R. E.. Strategic Management: a stakeholder approach. Marshfield: Pitman, 1984.

IBGE. Instituto Brasileiro de Geografia e Estatística. Censo agropecuário 2017. Brasília: IBGE, 2019.

JACKSON, T.. Macroeconomias ecológicas. In: JACKSON, T. Prosperidade sem crescimento: vida boa em um planeta finito. São Paulo: Abril, 2013. p.139-162.
KIM, L.. Cacao: impetus for the creation of an independent Venezuela. Emory Endeavors in World History, Atlanta, v.1, 2007.

KING, K. F. S.; CHANDLER, M. T.. The wasted lands. Nairobi: ICRAF, 1978.

LIMA, A. C.; SIMÕES, R. F.. Teorias clássicas do desenvolvimento regional e suas implicações de política econômica: o caso do Brasil. Revista de Desenvolvimento Econômico, Salvador, v.12, n.21, p.5-19, 2010.

LIMA, E. L.; SILVA NETO, P. J.. Aspectos gerais do cultivo do cacaueiro. In: MENDES, F. A. T.. A Cacauicultura na Amazônia: história, genética, pragas e economia. Belém: MAPA, 2017. p.9-54.

MARTA, J. M. C.. Rondônia: da colonização à integração Latino-Americana. Cuiabá: EdUFMT; Porto Velho: Edufro, 2018.

MENDONÇA, M. V.. Corredor ecológico entre as áreas protegidas de Carajás e da Terra do Meio, Pará. Dissertação (Mestrado em Desenvolvimento Regional) - Universidade Federal do Tocantins, Palmas, 2019.

NASCIMENTO, L. F.. Gestão ambiental e a sustentabilidade. Rio Grande do Sul: UAB, 2008.

NIETHER, W.; FUCHS, M.; SCHNEIDER, M.; ARMENGOT, L.. Below- and aboveground production in cocoa monocultures and agroforestry systems. Science of the Total Environment, Amsterdam, v.657, p.558-567, 2019. DOI: https://doi.org/10.1016/j.scitotenv.2018.12.050

OFORI, A.; PADI, F. K.; ANSAH, F. O.; AKPERTEY, A.; ANIMKWAPONG, G. J.. Genetic variation for vigour and yield of cocoa (Theobroma cacao L.) clones in Ghana. Scientia Horticulturae, v.213, p.287-293, 2016. DOI: https://doi.org/10.1016/j.scienta.2016.11.003

OKE, D. O.; ODEBIYI, K. A.. Traditional cocoa-based agroforestry and forest species conservation in Ondo State, Nigeria. Agriculture, Ecosystems \& Environment, Amsterdam, v.122, n.3, p.305-311, 2007. DOI: https://doi.org/10.1016/j.agee.2007.01.022

POWIS, T. G.; CYPHERS, A.; GAIKWAD, N. W.; GRIVETTI, L.; CHEONG, K.. Cacao use and the San Lorenzo Olmec. PNAS, Washington, v.108, n.21, p.8595-8600, 2011. DOI: https://doi.org/10.1073/pnas.1100620108

PRADO JÚNIOR, C.. História econômica do Brasil. São Paulo: Brasiliense, 1978.

RIBEIRO, G. L.. Poder, redes e ideologia no campo do desenvolvimento. Novos estudos CEBRAP, São Paulo, n.80, p.109-125, 2008. DOI: http://dx.doi.org/10.1590/S0101$\underline{33002008000100008}$

RODRIGUES SOBRINHO, F. C.; ALMEIDA, C. M. V. C.; DESTRO, W.. CEPLAC Rondônia: 40 anos de história e realizações. Porto Velho: CEPLAC, 2011.

SÁ SILVA, J. R.; ALMEIDA, C. D.; GUINDANI, J. F.. Pesquisa documental: pistas teóricas e metodológicas. Revista 
Brasileira de História e Ciências Sociais, São Paulo, v.1, n.1, 2009.

SANTOS, A. J.; LEAL, A. C.; GRAÇA, L. R.; CARMO, A. P. C.. Viabilidade econômica do sistema agroflorestal grevílea $x$ café na região norte do Paraná. Cerne, Lavras, v.6, n.1, p.89100, 2000.

SEIBERT, G.. Colonialismo em São Tomé e Príncipe: hierarquização, classificação e segregação da vida social. Anuário Antropológico, Brasília, v.2, p.99-120, 2015. DOI: http://doi.org/10.4000/aa.1411

SILVA NETO, P. J.; MATOS, P. G. C.; MARTINS, A. C. S.; SILVA, A. P.. Sistema de produção de cacau para a Amazónia brasileira. Belém, CEPLAC, 2001.

SILVA, S. U. P.; PAULETTO, D.; MOTA, C. G.; NASCIMENTO, G. C. S.; SANTOS, J. A. C.; RODE, R.; NOCE, R.. Viabilidade econômica de sistemas agroflorestais em Novo Progresso (PA). Revista Ibero Americana de Ciências Ambientais, Aracaju, v.9, n.6, p.28-36, 2018. DOI: https://doi.org/10.6008/CBPC2179-6858.2018.006.0003

SOUZA, N. J.. Teoria dos polos, regiões inteligentes e sistemas regionais de inovação. Análise, Porto Alegre, v.16, n.1, 2005.

SYDENSTRICKER NETO, J. M.. Parceleiros de Machadinho: história migratória e as interações entre a dinâmica demográfica e o ciclo agrícola em Rondônia. Dissertação (Mestrado em Sociologia) - Universidade Estadual de Campinas, Campinas, 1992.

TEIXEIRA NETO, E.. Os arranjos institucionais no sistema agroindustrial do cacau em Linhares-ES. Dissertação (Mestrado em Agronegócio e Desenvolvimento) Universidade Estadual Paulista "Júlio de Mesquita Filho", Tupã, 2017.
TRIVINOS, A. N. S.. Introdução à pesquisa em ciências sociais: a pesquisa qualitativa em educação. São Paulo: Atlas, 1987.

VALLENILLA, N. H.. The Eastern Venezuela Pioneer Front, 1830s-1930s: the role of the Corsican Trade Network. In: CLARENCE-SMITH, W. G.. Cocoa pioneer fronts since 1800. London: Palgrave Macmillan, 1996. p.23-44. DOI: https://doi.org/10.1007/978-1-349-24901-5 2

VAN LEEUWEN, J.; MENEZES, J. M. T.; GOMES, J. B. M.; IRIARTE-MARTEL, J. H.; CLEMENT, C. R.. Sistemas Agroflorestais para a Amazônia: importância e pesquisas realizadas. In: NODA, H.; SOUZA, L. A. G.; FONSECA, O. J. M.. Duas décadas de contribuições do INPA à pesquisa agronômica no trópico úmido. Manaus: INPA, 1999. p.131146.

WASC. World Atlas Statistics by Country. Cocoa bean: producing countries (tons). WASC, 2016.

YOSIE, T. F.; HERBST, T. D.. Using stakeholder processes in Environmental decisionmaking: an evaluation of lessons learned, key issues, and future challenges. Washington: GDRC, 1998.

ZARRILLO, S.; GAIKWAD, N.; LANAUD, C.; POWIS, T.; VIOT, C.; LESUR, I.; FOUET, O.; ARGOUT, X.; GUICHOUX, E.; SALIN, F.; SOLORZANO, R. L.; BOUCHEZ, O.; VIGNES, H.; SEVERTS, P.; HURTADO, J.; YEPEZ, A.; GRIVETTI, L.; BLAKE, M.; VALDEZ, F.. The use and domestication of Theobroma cacao during the mid-holocene in the upper Amazon. Nature, Ecology \& Evolution, London, v.2, p.1879-1888, 2018. DOI: https://doi.org/10.1038/s41559-018-0697-x

ZUGAIB, A. C. C.; BARRETO, R. C.. Mercado brasileiro de cacau: perspectiva de demanda, oferta e preços. Agrotrópica, Itabuna, n.3, v.27, p.303-316, 2015.

A CBPC - Companhia Brasileira de Produção Científica (CNPJ: 11.221.422/0001-03) detém os direitos materiais desta publicação. Os direitos referem-se à publicação do trabalho em qualquer parte do mundo, incluindo os direitos às renovações, expansões e disseminações da contribuição, bem como outros direitos subsidiários. Todos os trabalhos publicados eletronicamente poderão posteriormente ser publicados em coletâneas impressas sob coordenação da Sustenere Publishing, da Companhia Brasileira de Produção Científica e seus parceiros autorizados. Os (as) autores (as) preservam os direitos autorais, mas não têm permissão para a publicação da contribuição em outro meio, impresso ou digital, em português ou em tradução. 